\begin{tabular}{|c|c|c|}
\hline $\begin{array}{l}\text { Christine L. Klassen, MD } \\
\text { Assistant Professor of Medicine, Division } \\
\text { of General Internal Medicine, Mayo Clinic, } \\
\text { Rochester, MN }\end{array}$ & $\begin{array}{l}\text { Elizabeth Gilman, MD } \\
\text { Assistant Professor of Laboratory Medicine and } \\
\text { Pathology, Department of Laboratory Medicine } \\
\text { and Pathology, Mayo Clinic, Rochester, MN }\end{array}$ & $\begin{array}{l}\text { Aparna Kaur, MD } \\
\text { Instructor in Medicine, Division of General } \\
\text { Internal Medicine, Mayo Clinic, } \\
\text { Rochester, MN }\end{array}$ \\
\hline $\begin{array}{l}\text { Sara P. Lester, MD } \\
\text { Instructor in Medicine, Division of General } \\
\text { Internal Medicine, Mayo Clinic, } \\
\text { Rochester, MN }\end{array}$ & \multicolumn{2}{|c|}{$\begin{array}{l}\text { Sandhya Pruthi, MD } \\
\text { Professor of Medicine, Division of General Internal } \\
\text { Medicine, Mayo Clinic, Rochester, MN; President, } \\
\text { National Consortium of Breast Centers, Warsaw, IN; } \\
\text { Member, National Comprehensive Cancer Network } \\
\text { Breast Cancer Risk Reduction Advisory Committee }\end{array}$} \\
\hline
\end{tabular}

\title{
Breast cancer risk evaluation for the primary care physician
}

\section{ABSTRACT}

Primary care physicians are typically the front-line clinicians who assess female patients for their risk of breast cancer, doing so by using a combination of risk algorithms and collecting personal and family medical histories. Patients found to be at increased risk of breast cancer, defined as $>20 \%$ overall lifetime risk, are candidates for enhanced screening. This review notes risk factors, determinants of risk, and a systematic approach for primary care physicians to assess and manage patients at risk of breast cancer.

\section{KEY POINTS}

A personalized risk assessment for breast cancer should be performed in all female patients, using a combination of risk calculators and collecting a complete history of breast cancer risk factors.

Known breast cancer risk factors include genetic mutations, previous exposure to thoracic radiation, older age, obesity, breast density, and a first-degree relative with a history of breast cancer.

Many breast cancer risk calculators are available, with strengths, weaknesses, and variables that impact the primary care physician's efficiency and accuracy in determining screening and care.

Two commonly used risk calculators include the National Cancer Institute Breast Cancer Risk Assessment Tool, or Gail Model, and the International Breast Cancer Intervention study, or Tyrer-Cuzick Risk Model.
B REAST CANCER (BC) is the most commonly diagnosed cancer in women in the United States and the second most common cause of female cancer deaths. ${ }^{1}$ As such, many female patients present to primary care physicians for further guidance regarding their concerns and risks of developing BC. Risk assessment involves a significant amount of time to complete with many available risk calculation models, all of which have varied limitations. ${ }^{2-5}$

However, a personalized risk assessment for $\mathrm{BC}$ should be performed, to some degree, in all female patients using a combination of risk calculators and obtaining a complete medical history of BC risk factors. Approaching patients systematically; gathering basic information such as age, body mass index (BMI), family BC history, reproductive risk factors; and gathering specific risk factors such as known genetic mutations, prior chest radiation, or history of atypical hyperplasia or lobular carcinoma in situ (LCIS) can help determine which patients need more formal and in-depth evaluation. This can be undertaken by the primary care clinician or a high-risk BC specialist and lead to shared decision making regarding screening and risk-reduction strategies. Some patients need not undergo extensive BC risk calculation if already considered high risk.

It is prudent to consider the patient's personal values, individual risk factors, as well as differences in $\mathrm{BC}$ screening recommendations by societies and organizations (American Cancer Society [ACS], American College of Obstetrics and Gynecology, National Comprehensive Cancer Network [NCCN], and United States Preventative Services Task 
Force [USPSTF]). ${ }^{6-9}$ When individual risk is better understood, timing for appropriate initiation of screening, frequency of screening, implementation of lifestyle modifications for prevention, as well as recommendations for risk-reducing medications can be determined.

Patients who are found to be of high risk for $\mathrm{BC}$, defined as an overall lifetime risk greater than $20 \%$, are also candidates for enhanced BC screening. ${ }^{10}$ The ACS recommends that patients with elevated risk (based on family history risk calculations such as those from the International Breast Cancer Intervention study [IBIS]) should undergo annual magnetic resonance imaging (MRI) breast screening in addition to annual mammography, ${ }^{6}$ although this recommendation is not currently supported by USPSTF?

Recent American Society of Clinical Oncology, IBIS, and USPSTF recommendations, support the use of risk assessment to determine benefit of certain endocrine therapies (eg, tamoxifen, raloxifene, anastrozole) for postmenopausal female patients with one or more of the following: diagnosis of atypical (ductal or lobular) hyperplasia or LCIS, an estimated 5-year risk (National Cancer Institute [NCI] Breast Cancer Risk Assessment Tool [BCRAT]) $\geq 3 \%$, 10-year risk (IBIS/Tyrer-Cuzick risk calculator) $\geq 5 \%, 8,9,11$ or relative risk of $\geq 4$ times the population risk for their age group if 40 to 44 years old, or $>2$ times the population risk if 45 to 69 years old. ${ }^{8}$ Despite consistent national guidelines, less than $4 \%$ of candidates for endocrine therapy are currently prescribed these medications. ${ }^{12}$

In this article, we review BC risk factors, determinants of risk, and a pragmatic systematic approach to manage patients in the primary care setting.

\section{KNOWN BREAST CANCER RISK FACTORS}

\section{Gene mutations/hereditary breast and ovarian cancer genetic syndromes}

Approximately $8 \%$ to $10 \%$ of BCs are attributed to mutations in cancer susceptibility genes; more than $50 \%$ of germline mutations can be attributed to BReast CAncer gene (BRCA1) and BRCA2 mutations ${ }^{13,14}$ followed by mutations in genes such as checkpoint kinase 2 (CHEK2), ataxia-telangiectasia mutated (ATM), and part- ner and localizer of BRCA2 (PALB2). Despite the minority of $\mathrm{BCs}$ being attributable to genetics, $\mathrm{BC}$ attributable to mutations can be more lethal, and genetic counseling with discussion of genetic testing should be offered and available to patients with a significant family history of $\mathrm{BC}$ and/or ovarian cancer or known familial gene mutations, and in whom identifying a potential genetic mutation may change assessment and management options. ${ }^{13-15}$ For instance, patients with BRCA1 and BRCA2 should seriously consider surgical options for risk reduction, whereas $\mathrm{BC}$ from mutations in genes such as ATM, CDH1, CHEK2, NBN, NF1, PALB2, or STK11 can be followed by enhanced screening with breast MRI in conjunction with mammography. ${ }^{14,15}$ There are other gene mutations (such as BARD1, MSH2, MLH1, MSH6, PMS2, EPCAM, BRIP1, RAD51C, RAD51D) without clear evidence supporting increased lifetime risk of $\mathrm{BC}$, and thus guidelines for screening in these populations are unclear at this time. ${ }^{14}$

\section{History of high-risk breast lesions}

Atypical hyperplasia, which includes atypical ductal hyperplasia and atypical lobular hyperplasia as well as LCIS are characterized by dysplastic proliferation of epithelial mammary cells and differentiated based on histologic patterns and cytology seen on pathology. These patterns are significant risk factors for BC. Atypical hyperplasia is identified in around $10 \%$ of all benign breast biopsies. ${ }^{13,16,17}$

In the Mayo Benign Breast Disease Cohort and the Nashville Breast Cohort, incidence of $\mathrm{BC}$ in patients with atypical hyperplasia without chemoprevention was found to be around $1 \%$ to $2 \%$ per year ${ }^{17}$ with a cumulative incidence of $\mathrm{BC}$ of $30 \%$ at 25 years. ${ }^{18}$ Younger age at diagnosis of atypical hyperplasia is associated with increased likelihood of developing $\mathrm{BC}$, as is increased foci of atypical hyperplasia on pathology. ${ }^{18}$

LCIS is associated with an increased risk of $\mathrm{BC}$ to varying degrees from 3- to 8-fold higher risk when compared with the general population, regardless of whether the primary lesion has been removed. ${ }^{19}$ Using data from the $\mathrm{Na}$ tional Surgical Adjuvant Breast and Bowel Project P-1 Study, it was found that there was a $1.3 \%$ annual risk of development of invasive $\mathrm{BC}$ among patients with LCIS. ${ }^{20}$ 


\section{Personal history of thoracic radiation}

Ionizing radiation is a recognized risk factor for development of BC; this has been observed in the past in people exposed to atomic explosions such as Hiroshima or Nagasaki ${ }^{21}$ as well as in patients exposed to radiation treatments for diseases such as Hodgkin disease. ${ }^{22,23}$ Risk is inversely associated with age at radiation exposure and increased in women exposed to radiation before age 20 years compared with patients without a history of exposure. ${ }^{23-27}$ Personal risk in these patients has been shown to be as high as 56.7-fold greater than in the general population. ${ }^{28,29}$

Mantle radiation therapy is a form of extended field radiation and refers to radiation therapy that is administered to the mantle field that encompasses lymph nodes in the neck, chest, mediastinum, and axillary regions with the breast receiving about $3 \%$ to $15 \%$ of the administered dose. ${ }^{30}$

Most studies demonstrate increased BC risk 10 to 15 years following radiation treatment with development of secondary BC being rare within 10 years of treatment. ${ }^{27,30}$ Current guidelines recommend that patients who underwent thoracic radiation treatment between the ages of 10 and 30 begin annual screening MRI in addition to mammogram beginning 8 to 10 years after undergoing radiation treatment. ${ }^{9,29,31}$

\section{Age/menopause}

As more risk factors associated with $\mathrm{BC}$ are discovered, age remains one of the most significant. ${ }^{1,13} \mathrm{BC}$ is most frequently diagnosed among women ages 65 to 74 with median age of diagnosis at $63 .{ }^{16}$ Based on data from 2015 to $2017,12.9 \%$ of women will receive a diagnosis of $\mathrm{BC}$ at some point during their lifetime. ${ }^{16}$ Age-related $\mathrm{BC}$ risk according to the NCI Surveillance, Epidemiology, and End Results database between 2013 and 2017 shows increasing risk associated with each decade increase (Table 1). ${ }^{16}$

\section{Breast density}

Dense breast tissue is very common, with $35 \%$ to $50 \%$ of the population being categorized as having dense breast tissue based on American College of Radiology Breast Imaging Reporting and Database System scoring. ${ }^{32}$ Increased breast density has been shown to be an inde-

\begin{tabular}{|c|c|}
\hline $\begin{array}{l}\text { Age range } \\
\text { (years) }\end{array}$ & $\begin{array}{l}\text { New breast cancer } \\
\text { cases, } \%\end{array}$ \\
\hline $20-34$ & $1.9 \%$ \\
\hline $35-44$ & $8.2 \%$ \\
\hline $45-54$ & $19.2 \%$ \\
\hline $55-64$ & $25.6 \%$ \\
\hline $65-74$ & $26 \%$ \\
\hline $75-84$ & $13.7 \%$ \\
\hline$>84$ & $5.4 \%$ \\
\hline
\end{tabular}

pendent risk factor for the development of BC. The presence of extremely dense breast tissue on mammogram purports a 4- to 6-fold increase in $\mathrm{BC}$ risk compared with almost entirely fatty breast tissue. ${ }^{5}$ Owing to this significantly increased risk, breast density has been added to the most recent IBIS risk calculator and has been shown to increase accuracy of the model. ${ }^{5}$ In addition to increased BC risk with increased density, mammographic sensitivity is significantly decreased ${ }^{32}$; therefore, consideration of density as a component of risk, particularly in patients with other risk factors, is important.

\section{First-degree relatives with breast cancer}

Family history is a well-recognized risk factor for development of BC. A first-degree relative (eg, mother, sister, daughter) with BC increases an individual's relative risk of developing $\mathrm{BC}$ to 1.7 when compared with patients without an affected first-degree relative; this relative risk increases to 5 when two first-degree relatives are affected. ${ }^{13}$ Risk is further increased with younger age of diagnosed family members.

The risk ratio for $\mathrm{BC}$ was analyzed on the basis of number of first-degree relatives being affected, with a risk ratio of 1.80 (99\% floated confidence interval [FCI] 1.69-1.91) for patients with one affected first-degree relative having BC, 2.93 (99\% FCI 2.36-3.64) for patients with two first-degree relatives, and 3.90
A personalized risk assessment for BC should be performed, to some degree, in all female patients 
(99\% FCI 2.03-7.49) for patients with three or more first-degree relatives. ${ }^{33}$ Overall, $12.9 \%$ of patients with $\mathrm{BC}$ reported having at least one first-degree relative having $\mathrm{BC}$ whereas $7.3 \%$ of controls reported having at least one affected first-degree relative. ${ }^{33}$ Thus, while having a family history of $\mathrm{BC}$ in at least one first-degree relative increases $\mathrm{BC}$ risk, most patients with a family history of $\mathrm{BC}$ will not go on to develop BC themselves.

\section{Obesity}

Obesity is known to be correlated with increased risk of several malignancies, including $\mathrm{BC} .{ }^{34}$ The types of $\mathrm{BC}$, namely hormone receptor (HR)-positive or $\mathrm{HR}$-negative $\mathrm{BC}$ and the association with obesity can be further stratified by menopausal status. Obese premenopausal patients have not been shown to be at increased risk of HR-positive malignancy; however, they do appear to be at an increased risk of HR-negative/triple-negative and inflammatory cancers. ${ }^{34}$

Obese postmenopausal patients, however, are at a significantly increased risk of HR-positive BC. ${ }^{35}$ The Million Woman Study followed 1.2 million women in the United Kingdom

Patients found to be of high risk for $B C$, defined as overall lifetime risk $>20 \%$, are candidates for enhanced BC screening and demonstrated a 39\% increased risk of HRpositive $\mathrm{BC}$ for postmenopausal women with a $\mathrm{BMI} \geq 30 .{ }^{35}$ Others have demonstrated that increased waist circumference and waist-to-hip ratio are also indicative of an increased risk for estrogen receptor (ER)-positive/progesterone receptor (PR)-positive cancers. Similarly, data from the Women's Health Initiative Observational Study showed that patients with a BMI > 31.1 had an increased relative risk of postmenopausal BC (relative risk 2.52, 95\% CI 1.62-3.93) compared with women with a $\mathrm{BMI}<22.6{ }^{36}$ This association is postulated to be secondary to increased circulating estrogen levels and secondary to peripheral conversion of estrogen precursors to estrogen in adipose tissue despite the menopausal state resulting in decreased estrogen levels. ${ }^{37}$ Furthermore, hyperinsulinemia secondary to weight gain may increase growth factors and cytokine activation resulting in a microenvironment favorable to tumor development. Accordingly, postmenopausal obesity is not as clearly associated with HR-negative BC. ${ }^{34}$

Weight loss has been associated with lower
BC risk. ${ }^{34}$ Weight loss after 18 years as well as after menopause have both independently demonstrated a decrease in postmenopausal BC risk. ${ }^{34}$ Additionally, bariatric surgery was shown to reduce $\mathrm{BC}$ incidence at 5 years postoperatively. ${ }^{34}$ These data can be used to counsel patients regarding current risk, as well as possible incentive to pursue weight loss in the future.

\section{METHODS TO EVALUATE RISK}

\section{Breast cancer risk calculators}

Several BC risk calculators exist; however, few are used in clinical practice regularly. The two most commonly used BC risk calculators in the United States-and what we use regularly in our practice - are the National Cancer Institute BCRAT, also known as the Gail Model, and the IBIS/Tyrer-Cuzick Risk Model calculator. Both can be used to identify candidates for risk-reducing medications and for supplemental MRI screening. ${ }^{2,5,38-42}$

The BCRAT (https://bcrisktool.cancer. gov) is validated for patients ages 35 and older in many different populations ${ }^{2,38-40}$ but is not as useful for patients with a biopsy diagnosis of atypia as it underestimates overall risk. ${ }^{41}$ BCRAT can be used to calculate an estimated 5-year and lifetime risk and provide a population risk and not an individual risk assessment. It does not consider extensive family history, therefore is not recommended to determine need for enhanced screening with MRI.

The IBIS risk assessment tool (http://www. ems-trials.org/riskevaluator) considers reproductive history, body composition, and extensive family history; the most recent version includes mammographic breast density. A 5-year, 10 -year, and lifetime risk estimate is available for patients under the age of $85 .^{5}$ In contrast to the BCRAT, the IBIS calculator can be used to "qualify" patients for supplemental BC screening with MRI. However, this model tends to overestimate risk for patients with a biopsy diagnosis of atypia, and therefore, should not be used in this population. ${ }^{42}$

In the office setting, the BCRAT model offers a quick estimate of $\mathrm{BC}$ risk. However, the IBIS model is more comprehensive and includes a more in-depth family history. There are many models available including Claus, BRCAPRO and BOADICEA models. ${ }^{2-5}$ 


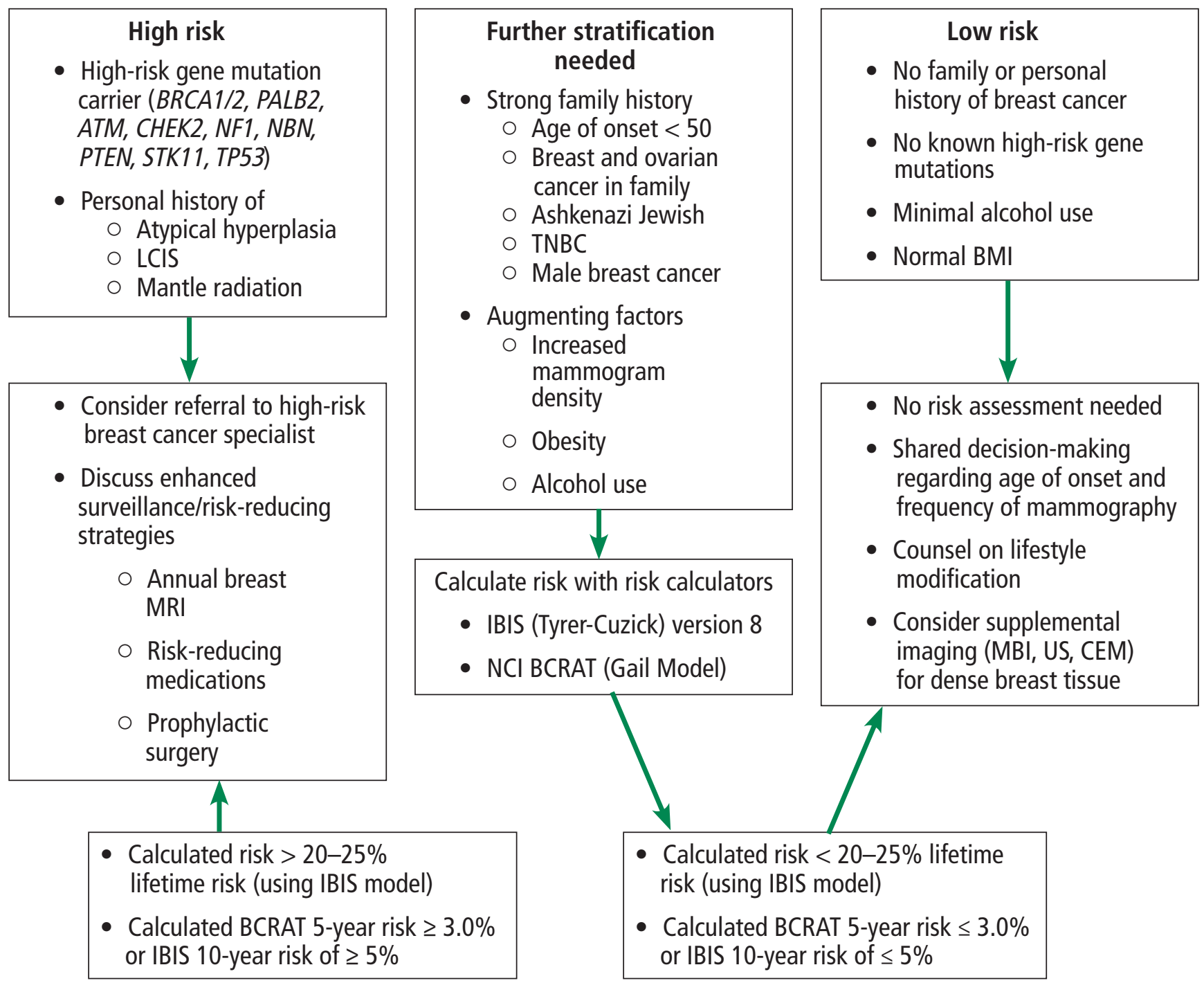

Figure 1. Systematic approach to breast cancer risk evaluation. A step-by-step approach to categorize patients who require further stratification vs patients needing referral to breast specialist.

ATM $=$ arabidopsis thaliana homeobox gene 1; BCRAT = Breast Cancer Risk Assessment Tool; BMI = body mass index; BRCA = BReast CAncer gene; $\mathrm{CEM}=$ contrast-enhanced mammogram; CHEK = checkpoint kinase 2; IBIS = International Breast Intervention Study; LCIS = lobular carcinoma in situ; $\mathrm{MBI}=$ molecular breast imaging; $\mathrm{MRI}=$ magnetic resonance imaging; $\mathrm{NBN}=$ nibrin; $\mathrm{NCl}=$ National Cancer Institute; NF1 = neurofibromin; PALB = partner and localizer of BRCA; PTEN = phosphatase and tensin homolog; STK = serine/threonine kinase; TNBC = triple-negative breast cancer; TP = tumor protein; US = ultrasonography

Data from references $6,7,9,11,29$, and 31 .

\section{A SYSTEMATIC APPROACH TO RISK EVALUATION}

There is no standard approach to initiate BC risk assessment in a primary care office setting. We recommend that clinicians periodically reassess $\mathrm{BC}$ risk factors, beginning with the patient's initial evaluation. Risk should be re-evaluated if patients have a family history of $\mathrm{BC}$ or ovarian cancer, and/or breast biopsy or baseline mammogram that demonstrates dense breast tissue, or if they present with a new diagnosis of cancer in the family. Assessment should include reproductive risk factors, prior high-risk breast lesions, exposure to ionizing radiation, lifestyle (eg, smoking, alcohol, diet, physical activity), and family history of 
cancer. Patients can then be divided into 3 major risk categories, with subsequent evaluation and recommendations appropriate to their level of risk (Figure 1).6,7,9,11,29,31

The first step of evaluation should be to identify patients who have clearly significantly increased risk for $\mathrm{BC}$ and who would benefit from a referral to a high-risk BC specialist for counseling and surveillance. This would include patients with a known gene mutation, history of thoracic radiation, personal history of atypical hyperplasia or LCIS on a biopsy, and/or strong family history of breast and ovarian cancer suggestive of a gene mutation. Owing to known increased $\mathrm{BC}$ risk for patients with these conditions as well as inaccuracy of models regarding this risk, these patients would likely benefit from consultation with a high-risk $\mathrm{BC}$ specialist to determine the type and frequency of BC screening, to discuss options such as prophylactic mastectomy and preventive medications, and to review indications for genetic consultation and testing. It has also been shown that female patients at high risk are more likely to take risk-reducing medications after a referral to medical oncology/high-risk BC specialists. ${ }^{43}$

In patients without the above-mentioned high-risk factors, we recommend considering other risk factors. The USPSTF recommends applying the use of a risk assessment tool for any female patient with a family history of $\mathrm{BC}$, ovarian, tubal, or peritoneal cancer or ancestrial association with BRCA1/2 gene mutations, such as Ashkenazi Jewish heritage. ${ }^{3}$ Additionally, the American College of Radiation and Society of Breast Imaging have recently published guidelines recommending that African American women undergo risk evaluation with consideration for genetic testing by the age of 30 years, ${ }^{44}$ including a discussion on supplemental screening with breast MRI for risk evaluation of all patients. ${ }^{44}$

For all patients, cancers on both maternal and paternal sides should be included in the history with special attention to $\mathrm{BC}$ at a young age and particular subtypes such as tri- ple negative $\mathrm{BC}, \mathrm{BC}$ in male family members, cancers in multiple sites. NCCN guidelines have been expanded to include family history in first-and second-degree relatives and potentially include extensive involvement of third-degree relatives. Additional risk factors discussed above can potentially augment that risk. Patients at higher risk could benefit the most from undergoing more formal $\mathrm{BC}$ risk stratification using the many validated $\mathrm{BC}$ risk assessment tools discussed above.

For patients who do not have significant family history but are found to have a higherrisk lifestyle (eg, obesity, smoking, excessive alcohol use), extensive risk evaluation with use of risk calculators is not necessarily needed. But these patients would clearly benefit from counseling regarding mitigation of these risk factors and reducing $\mathrm{BC}$ risk.

Some patients will come without any significant family history of BC or ovarian cancer and without significant lifestyle factors that contribute to $\mathrm{BC}$ risk. In this situation, no further risk stratification is indicated. We do recommend discussing society guidelines for BC screening in patients with average risk and using a shared decision-making approach to determining at what age and frequency patients undergo $\mathrm{BC}$ screening.

In conclusion, a systematic approach to risk assessment will allow the primary care clinician to identify female patients at high risk for $\mathrm{BC}$ and provide an opportunity for shared decision making regarding screening, enhanced screening, referrals to a specialty clinic, genetic counseling, and counseling on risk-reduction strategies including lifestyle modifications and risk-reducing medications. With knowledge and understanding of personal risks, patients may have a higher perceived benefit to intervention and are more likely to use risk-reducing treatment. ${ }^{43}$

\section{DISCLOSURES}

The authors report no relevant financial relationships which, in the context of their contributions, could be perceived as a potential conflict of interest. 


\section{KLASSEN AND COLLEAGUES}

\section{REFERENCES}

1. Siegel RL, Miller KD, Jemal A. Cancer statistics, 2020. CA Cancer J Clin 2020; 70(1):7-30. doi:10.3322/caac.21590

2. Gail MH, Brinton LA, Byar DP, et al. Projecting individualized probabilities of developing breast cancer for white females who are being examined annually. J Natl Cancer Inst 1989; 81(24):1879-1886. doi:10.1093/jnci/81.24.1879

3. Claus EB, Risch N, Thompson WD. Autosomal dominant inheritance of early-onset breast cancer: implications for risk prediction. Cancer 1994; 73:643-651. doi:10.1002/1097-0142(19940201)73:3<643::aid-cncr2820730323>3.0.co;2-5

4. Tice JA, Cummings SR, Smith-Bindman R, Ichikawa L, Barlow WE, Kerlikowske K. Using clinical factors and mammographic breast density to estimate breast cancer risk: development and validation of a new predictive model. Ann Intern Med 2008; 148(5):337-347. doi:10.7326/0003-4819-148-5-200803040-00004

5. Brentnall AR, Cuzick J, Buist DSM, Bowles EJA. Long-term accuracy of breast cancer risk assessment combining classic risk factors and breast density. JAMA Oncol 2018; 4(9):e180174. doi:10.1001/jamaoncol.2018.0174

6. Smith RA, Cokkinides V, Eyre HJ; American Cancer Society. American Cancer Society guidelines for the early detection of cancer, 2004. CA Cancer J Clin 2004; 54(1):41-52. doi:10.3322/canjclin.54.1.41

7. Siu AL; US Preventive Services Task Force. Screening for breast cancer: US Preventive Services Task Force recommendation statement. Ann Intern Med 2016; 164(4):279-296. doi:10.7326/M15-2886

8. Visvanathan $\mathrm{K}$, Fabian CJ, Bantug E, et al. Use of endocrine therapy for breast cancer risk reduction: ASCO clinical practice guideline update. J Clin Oncol 2019; 37(33):3152-3165. doi:10.1200/JCO.19.01472

9. Bevers TB, Anderson BO, Bonaccio E, et al. NCCN clinical practice guidelines in oncology: breast cancer screening and diagnosis. J Natl Compr Canc Netw 2009; 7(10):1060-1096.

doi:10.6004/jnccn.2009.0070

10. Saslow D, Boetes C, Burke W, et al. American Cancer Society guidelines for breast screening with MRI as an adjunct to mammography. Practice Guidelines. CA Cancer J Clin 2007; 57(2):75-89. doi:10.3322/canjclin.57.2.75

11. US Preventive Services Task Force, Owens DK, Davidson KW, et al. Medication use to reduce risk of breast cancer: US Preventive Services Task Force recommendation statement. JAMA 2019; 322(9):857-867. doi:10.1001/jama.2019.11885

12. Amir E, Seruga B, Martinez-Lopez J, et al. Oncogenic targets, magnitude of benefit, and market pricing of antineoplastic drugs. J Clin Oncol 2011; 29(18):2543-2549. doi:10.1200/JCO.2011.35.2393

13. Bland KI, Copeland EM, Klimberg VS, Gradishar WJ. The Breast: Comprehensive Management of Benign and Malignant Diseases. 5th ed. Philadelphia, PA: Elsevier; 2018.

14. Manahan ER, Kuerer HM, Sebastian M, et al. Consensus guidelines on genetic testing for hereditary breast cancer from the American Society of Breast Surgeons. Ann Surg Oncol 2019; 26(10):3025-3031. doi:10.1245/s10434-019-07549-8

15. Daly MB, Pilarski R, Yurgelun MB, et al. NCCN guidelines insights. Genetic/familial high-risk assessment: breast, ovarian, and pancreatic, version 1.2020. J Natl Compr Canc Netw 2020; 18(4):380-391. doi:10.6004/jnccn.2020.0017

16. National Cancer Institute. Surveillance, Epidemiology, and End Results (SEER) Program. https://seer.cancer.gov/statfacts/html/breast. html. Accessed February 8, 2022.

17. Degnim AC, Winham SJ, Frank RD, et al. Model for predicting breast cancer risk in women with atypical hyperplasia. J Clin Oncol 2018; 36(18):1840-1846. doi:10.1200/JCO.2017.75.9480

18. Hartmann LC, Degnim AC, Santen RJ, Dupont WD, Ghosh K. Atypical hyperplasia of the breast-risk assessment and management options. N Engl J Med 2015; 372(1):78-89. doi:10.1056/NEJMsr1407164

19. Coopey SB, Mazzola E, Buckley JM, et al. The role of chemoprevention in modifying the risk of breast cancer in women with atypical breast lesions. Breast Cancer Res Treat 2012; 136(3):627-633. doi:10.1007/s10549-012-2318-8
20. Fisher B, Costantino JP, Wickerham DL, et al. Tamoxifen for prevention of breast cancer: report of the National Surgical Adjuvant Breast and Bowel Project P-1 study. J Natl Cancer Inst 1998; 90(18):1371-1388. doi:10.1093/jnci/90.18.1371

21. Tokunaga M, Land CE, Tokuoka S, Nishimori I, Soda M, Suminori A. Incidence of female breast cancer among atomic bomb survivors, $\mathrm{Hi}$ roshima and Nagasaki, 1950-1985. Radiat Res 1994; 138(2):209-223. PMID:8183991

22. Aisenberg AC, Findelstein DM, Doppke DP, Koerner FC, Boivin JF, Willett CG. High risk of breast carcinoma after irradiation of young women with Hodgkin's disease. Cancer 1997; 79(6):1203-1210. doi:10.1002/(sici)1097-0142(19970315)79:6<1203::aid-cncr20>3.0.co;2-2.

23. Hill DA, Preston-Martin S, Ross RK, Bernstein L. Medical radiation, family history of cancer, and benign breast disease in relation to breast cancer risk in young women, USA. Cancer Causes Control 2002; 13(8):711-718. doi:10.1023/a:1020201106117

24. Henderson TO, Amsterdam A, Bhatia S, et al. Systematic review: surveillance for breast cancer in women treated with chest radiation for childhood, adolescent, or young adult cancer. Ann Intern Med 2010; 152:444-455; W144-54. doi:10.7326/0003-4819-152-7-201004060-00009

25. De Bruin ML, Sparidans J, van't Veer MB, et al. Breast cancer risk in female survivors of Hodgkin's lymphoma: lower risk after smaller radiation volumes. J Clin Oncol 2009; 27(26):4239-4246. doi:10.1200/JCO.2008.19.9174

26. Tinger A, Wasserman TH, Klein EE, et al. The incidence of breast cancer following mantle field radiation therapy as a function of dose and technique. Int J Radiat Oncol Biol Phys 1997; 37(4): 865-870. doi:10.1016/s0360-3016(97)00026-6

27. Allen SD, Wallis MG, Cooke R, Swerdlow AJ. Radiologic features of breast cancer after mantle radiation therapy for Hodgkin disease: a study of 230 cases. Radiology 2014; 272(1):73-78. doi:10.1148/radiol.14131789

28. Bhatia S, Yasui Y, Robison LL, et al. High risk of subsequent neoplasms continues with extended follow-up of childhood Hodgkin's disease: report from the Late Effects Study Group. J Clin Oncol 2003; 21(23):4386-4394. doi:10.1200/JCO.2003.11.059

29. Bevers TB, Helvie M, Bonaccio E, et al. National Comprehensive Cancer Network breast cancer screening and diagnosis, version 3.2018: Clinical Practice Guidelines in Oncology. J Natl Compr Canc Netw 2018; 16(11):1362-1389. doi:10.6004/jnccn.2018.0083

30. van Leeuwen FE, Klokman WJ, Stovall M, et al. Roles of radiation dose, chemotherapy, and hormonal factors in breast cancer following Hodgkin's disease. J Natl Cancer Inst 2003; 95(13):971-980. doi:10.1093/jnci/95.13.971

31. National Comprehensive Cancer Network. NCCN Clinical Practice Guidelines in Oncology. Breast Cancer Screening and Diagnosis. Version 1.2021. May 6, 2021. https://www.nccn.org/guidelines/guidelines-detail?category=2\&id=1421. Accessed February 8, 2022.

32. Hruska CB. Molecular breast imaging for screening in dense breasts: state of the art and future directions. AJR Am J Roentgenol 2017; 208(2):275-283. doi:10.2214/AJR.16.17131.

33. Collaborative Group on Hormonal Factors in Breast Cancer. Familial breast cancer: collaborative reanalysis of individual data from 52 epidemiological studies including 58,209 women with breast cancer and 101,986 women without the disease. Lancet 2001; 358(9291):1389-1399. doi:10.1016/S0140-6736(01)06524-2

34. Picon-Ruiz M, Morata-Tarifa C, Valle-Goffin JJ, Friedman ER, Slingerland JM. Obesity and adverse breast cancer risk and outcome: mechanistic insights and strategies for intervention. CA Cancer J Clin 2017; 67(5):378-397. doi:10.3322/caac.21405

35. Reeves GK, Pirie K, Beral V, Green J, Spencer E, for Million Women Study Collaborators. Cancer incidence and mortality in relation to body mass index in the Million Women study: cohort study. BMJ 2007; 335(7630):1134. doi:10.1136/bmj.39367.495995.AE

36. Morimoto LM, White E, Chen Z, et al. Obesity, body size, and risk of postmenopausal breast cancer: the Women's Health Initiative (United States). Cancer Causes Control 2002; 13(8):741-751. doi:10.1023/a:1020239211145 
37. Key TJ, Appleby PN, Reeves GK, et al. Body mass index, serum sex hormones, and breast cancer risk in postmenopausal women. J Nat Cancer Inst 2003; 95(16):1218-1226. doi:10.1093/jnci/djg022

38. Gail MH, Costantino JP, Pee D, et al. Projecting individualized absolute invasive breast cancer risk in African American women. J Natl Cancer Inst 2007; 99(23):1782-1792. doi:10.1093/jnci/djm223

39. Matsuno RK, Costantino JP, Ziegler RG, et al. Projecting individualized absolute invasive breast cancer risk in Asian and Pacific Islander American women. J Natl Cancer Inst 2011; 103(12):951-961. doi:10.1093/jnci/djr154

40. Banegas MP, John EM, Slattery ML, et al. Projecting individualized absolute invasive breast cancer risk in US Hispanic women. J Natl Cancer Inst 2017; 109(2):1-8. doi:10.1093/jnci/djw215

41. Pankratz VS, Hartmann LC, Degnim AC, et al. Assessment of the accuracy of the Gail model in women with atypical hyperplasia. J Clin Oncol 2008; 26(33):5374-5379. doi:10.1200/JCO.2007.14.8833
42. Boughey JC, Hartmann LC, Anderson SS, et al. Evaluation of the Tyrer-Cuzick (International Breast Cancer Intervention Study) model for breast cancer risk prediction in women with atypical hyperplasia. J Clin Oncol 2010; 28(22):3591-3596. doi:10.1200/JCO.2010.28.0784

43. Trivedi MS, Coe AM, Vanegas A, Kukafka R, Crew KD. Chemoprevention uptake among women with atypical hyperplasia and lobular and ductal carcinoma in situ. Cancer Prev Res (Phila) 2017; 10(8):434-441. doi:10.1158/1940-6207.CAPR-17-0100

44. Monticciolo DL, Newell MS, Moy L, Niell B, Monsees B, Sickles EA Breast cancer screening in women at higher-than-average risk: recommendations from the ACR. J Am Coll Radiol 2018; 15 (3 pt A):408-414. doi:10.1016/j.jacr.2017.11.034

Address: Christine L. Klassen, MD, Assistant Professor of Medicine, Division of General Internal Medicine, Mayo Clinic, 200 First Street, SW, Rochester, MN 55905; Klassen.christine@mayo.edu 